\title{
Review
}

\section{Recognition of self and altered self by $T$ cells in autoimmunity and allergy}

\author{
Lei Yin ${ }^{1 \bowtie}$, Shaodong Dai ${ }^{2}$, Gina Clayton ${ }^{1}$, Wei Gao ${ }^{2}$, Yang Wang ${ }^{2}$, John Kappler ${ }^{1,3}$, Philippa Marrack ${ }^{1,4 \bowtie}$ \\ ${ }^{1}$ Howard Hughes Medical Institute and Integrated Department of Immunology, National Jewish Health, Denver, CO 80206 , \\ USA \\ ${ }^{2}$ Integrated Department of Immunology, National Jewish Health, Denver, CO, 80206, USA \\ ${ }^{3}$ Program in Structural Biology and Biophysics, University of Colorado Denver, School of Medicine, Aurora, CO 80045, USA \\ ${ }^{4}$ Department of Biochemistry and Molecular Genetics, University of Colorado Denver, School of Medicine, Aurora, CO 80045, \\ USA \\ $\triangle$ Correspondence: yinl@njhealth.org (L. Yin), marrackp@njhealth.org (P. Marrack) \\ Received July 26, 2012 Accepted November 23, 2012
}

\begin{abstract}
$T$ cell recognition of foreign peptide antigen and tolerance to self peptides is key to the proper function of the immune system. Usually, in the thymus $\mathrm{T}$ cells that recognize self $\mathrm{MHC}+$ self peptides are deleted and those with the potential to recognize self $\mathrm{MHC}+$ foreign peptides are selected to mature. However there are exceptions to these rules. Autoimmunity and allergy are two of the most common immune diseases that can be related to recognition of self. Many genes work together to lead to autoimmunity. Of those, particular MHC alleles are the most strongly associated, reflecting the key importance of MHC presentation of self peptides in autoimmunity. T cells specific for combinations of self MHC and self peptides may escape thymus deletion, and thus be able to drive autoimmunity, for several reasons: the relevant self peptide may be presented at low abundance in the thymus but at high level in particular peripheral tissues; the relevant self peptide may bind to MHC in an unusual register, not present in the thymus but apparent elsewhere; finally the relevant self peptide may be post translationally modified in a tissue specific fashion. In some types of allergy, the peptide + MHC combination may also be fully derived from self. However the combination in question may be modified by the presence of other ligands, such as small drug molecules or metal ions. Thus these types of allergies may act like the post translationally modified peptides involved some types of autoimmunity.
\end{abstract}

KEYWORDS altered self, neoantigen, antigen present- ing, T cell recognition, autoimmunity, allergy, diabetes, dermatitis, drug hypersensitivity

\section{INTRODUCTION}

The so-called alpha beta $\mathrm{T}$ cell receptors (TCRs) for foreign antigen are composed of two chains, alpha and beta. The genes coding for these chains are created by gene rearrangement in thymocytes. In mice, any given receptor may contain a TCR alpha chain (TCRa) made up of any one of between 70 and 107 Valphas (Vas), and any one of about 50 Jalphas (Jas). The number of combinations of these two elements is $\sim 100 \times 50=5,000$, indicating that the germ line TCR alpha locus can code for about 5000 different TCRa chains. However, when Va genes rearrange to lie next to a Ja gene, nucleotides can be removed or added, resulting in considerable variability in the DNA sequence, and therefore amino acid sequence, at this junction. This very variable junction lies within what is known as the CDR3 loop of the TCRa chain (Fig.1) and random DNA sequences in this junction increase the total number of possible TCR $\alpha$ chain protein sequences that can occur in an animal by several orders of magnitude, to $\sim 10^{7}$. Similar phenomena apply to rearrangements for the TCR beta (TCR $\beta$ ) chain locus, leading to, again, a very large number of possible TCR $\beta$ chain sequences (Fig. 1).

These TCRs usually react with foreign antigens in the form of peptides from the foreign material bound to major histocompatibililty complex proteins (MHC). An example of the structure of the combination is shown in Fig. 2. The foreign peptide fills the groove of MHC and the TCR lies above the two in an approximately diagonal orientation, as previously reported (Garcia et al., 1996, 1998, 1999; Reiser et al., 2003; 

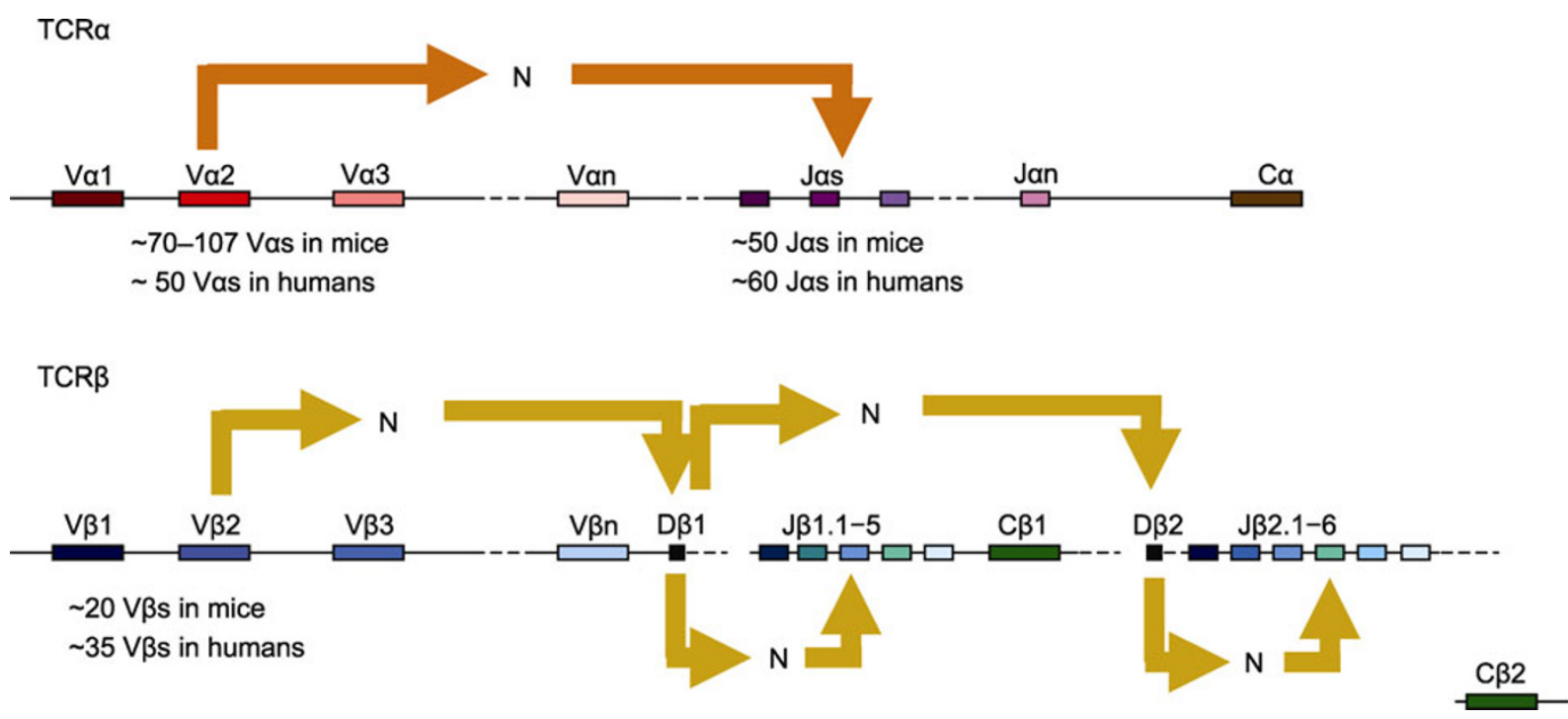

Figure 1. Diagram of the rearrangements that give rise to genes coding for T cell receptor alpha and beta polypeptides. Shown are diagrams of the arrangement of variable $(V)$, diversity $(D)$, joining $(\mathrm{J})$ and constant $(\mathrm{C})$ regions for $\mathrm{T}$ cell receptor alpha and beta chains. Arrows indicate rearrangement patterns and $\mathrm{N}$ indicates the sites at which nucleotides are removed or added. Also indicated are the approximate numbers of each genetic element in the mouse and human genome.

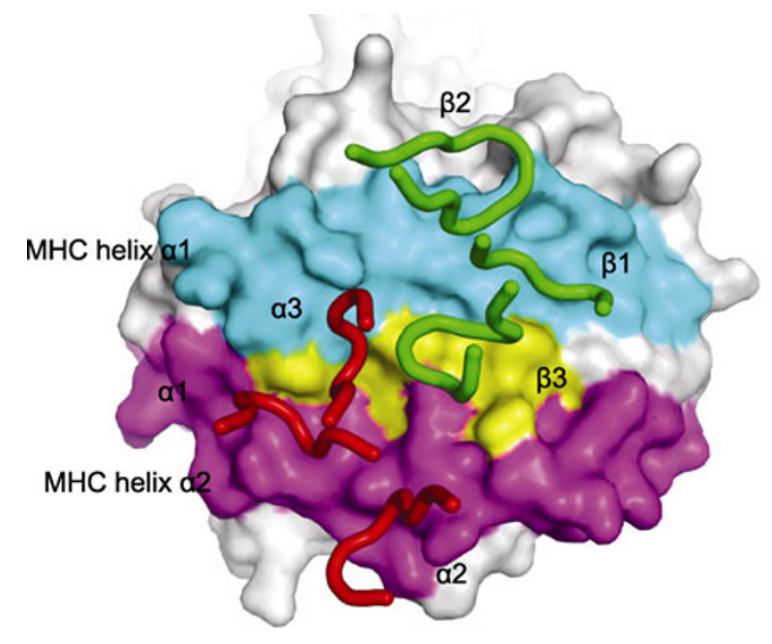

Figure 2. Illustration of the position of T cell receptor CDR regions on an MHC + peptide ligand. Shown are the positions of the TCR alpha and beta chain CDR regions ( $\alpha 1-\alpha 3$ and $\beta 1-\beta 3$ respectively) of the YAe62.8 TCR bound to the mouse $\mathrm{MHCl}$ protein, $\mathrm{K}^{\mathrm{b}}$ and the $\mathrm{pWM}$ peptide. The CDR loops are colored red (CDRa1-3) and green (CDRß1-3). The alpha helices of $K^{b}$ are colored cyan ( $\alpha 1$ ) and magenta ( $\alpha 2$ ) and the pWM peptide is colored yellow. The peptide has been truncated in the Figure to remove amino acid residues of the linker that covalently binds the peptide to $\mathrm{K}^{\mathrm{b}}$. This Figure is a modified version of a Figure in Yin et al. (2011a).

Maynard et al., 2005; Tynan et al., 2005; Colf et al., 2007; Feng et al., 2007; Tynan et al., 2007; Dai et al., 2008; Marrack et al., 2008; Garcia et al., 2009; Burrows et al., 2010;
Day et al., 2011; Yin et al., 2011a). This allows the loops at the ends of the TCR $\alpha$ and TCR $\beta$ beta strands to contact both $\mathrm{MHC}$ and foreign peptide, with the CDR1 and CDR2 sequences (which are encoded in the germ line DNA for $\mathrm{Va}$ and $\mathrm{V} \beta$ respectively) contacting mostly the alpha helices of the MHC proteins themselves. However, the CDR3 regions of TCR $\alpha$ and TCR $\beta$ (which are encoded by the random, non germline sequences that are created by gene rearrangement) make many contacts with the foreign peptide.

In order for $\mathrm{T}$ cells to divide and be activated to perform their various functions, cell killing, cytokine production etc., the TCR on the T cell must engage its ligand, a ligand that is composed, as discussed above, of a self MHC protein bound to a foreign peptide and "presented" on the surface of an antigen presenting cell. At the beginning stages of the $T$ cell response, the antigen presenting cell is usually a dendritic cell (Steinman and Inaba, 1985; Steinman et al., 1988; Inaba et al., 1990; Banchereau and Steinman, 1998). The reaction delivers so-called Signal 1 to the T cell. Signal 1 alone is not usually sufficient to trigger the $\mathrm{T}$ cell into full activity, however. $\mathrm{T}$ cells usually need to receive additional, so-called co-stimulatory signals, with so-called Signal 2 delivered by interaction between proteins such as CD28 on the T cell and B7-related proteins on the antigen presenting cell (Alarcon et al.; Watts; Lafferty and Cunningham, 1975; Jenkins and Schwartz, 1987; Bluestone, 1995; Sharpe, 2009) and Signal 3 coming from some inflammatory stimulus, cytokines such as IL-1, IL-6, TNFa and their relatives or perhaps from engagement of Toll like receptors and other systems for generic detection of invading organisms (Hintzen et al., 1994; Dinarello, 2002; Dolfi and Katsikis, 2007; Croft, 2009) (Fig 3). 


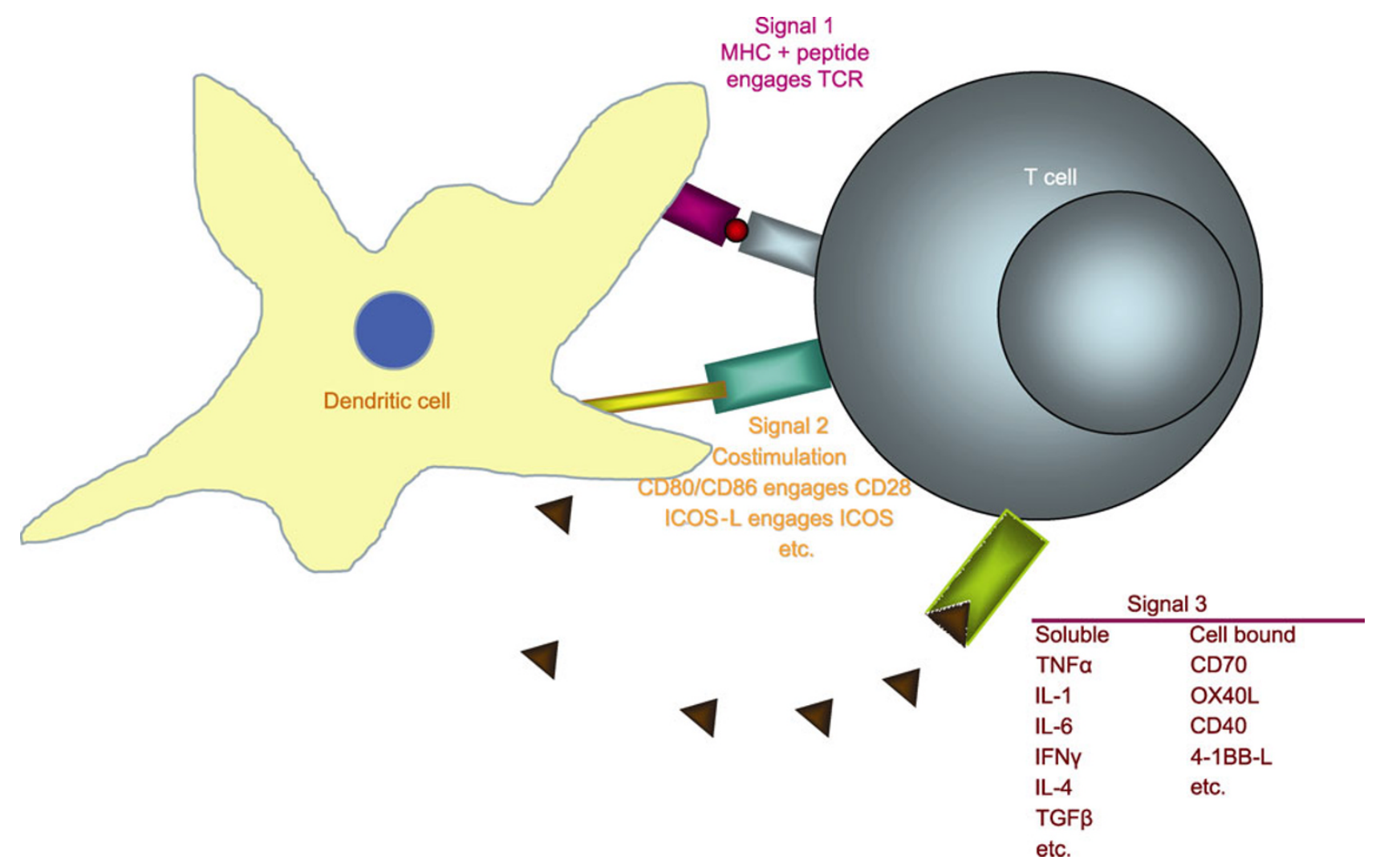

Figure 3. T cells need three signals for productive responses. Shown are the three signals that are thought to be needed for $T$ cells to respond well to antigen. These include Signal 1, derived from engagement of the T cell's TCR, Signal 2, thought to be often delivered through receptors on the T cell surface such as CD28 and ICOS and Signal 3, thought to be often derived from cytokines or cell bound ligands that are produced in response to inflammation.

Any given animal could contain a very large number of different TCRs, each expressed on a different T cell. How is it that these TCRs don't recognize self peptides, peptides from the proteins of their own host, bound to the host's MHC proteins? Several phenomena prevent such potentially lethal interactions. Of these the first to be firmly established was the phenomenon of clonal deletion in the thymus. Thymocytes bearing TCRs that react too well with MHC + peptide combinations and other ligands that appear in the thymus die (Kappler et al., 1987; Bluthmann et al., 1988). Thus these cells cannot convert into mature functional $T$ cells and hurt their hosts. In spite of clonal deletion, some potentially autoreactive $T$ cells escape the thymus. These are held in check by at least three controls: regulatory $T$ cells (Wildin et al., 2002; Gambineri et al., 2003; Ramsdell, 2003); clonal exhaustion, induced by prolonged exposure to antigen (Wherry et al. 2007) or anergy, a state of unresponsiveness induced by a failure to deliver signal 2 or signal 3 (Sloan-Lancaster and Allen, 1995; Wherry et al., 2007) (Fig. 3). This last controlling mechanism has been harnessed recently in cancer therapies, in which blockade of CTLA4 or PD1, proteins that inhibit co-stimulation by Signal 2 (Fig. 3) allows resumed autoattack by $\mathrm{T}$ cells of tumor cells (Callahan et al., et al., 2010; Pardoll, 2012).

\section{WHAT ALLOWS T CELLS TO REACT WITH SELF ANTIGENS AND THUS DRIVE AUTOIMMUNITY?}

Autoimmune disease occurs in spite of the many ways in which potentially autoreactive $T$ and B cells are deleted or inactivated. Sometimes disease occurs because one or more of the controlling mechanisms fails. For example, mice and humans lacking Fas, a protein that contributes to the death of activated lymphocytes, develop lymphadenopathy and autoimmunity (Dhein et al., 1995; Sneller et al., 1997). Likewise animals lacking AIRE, a protein that affects T cell tolerance in the thymus, develop what is known as autoimmune polyendocrinopathy-candidiasis-ectodermal dystrophy syndrome (APECED). This disease drives the appearance of autoantibodies against the products of many tissues and thus autoattack on many different organs of the body. Interestingly, APECED patients also produce antibodies against cytokines such as IL-17A, IL-17F and IL-22, a phenomenon that might be the cause of their frequent infection with candida (Browne and Holland; Heino et al., 2001; Anderson et al., 2002; Ramsey et al., 2002). 
In humans, most autoimmunity is not caused by mutations in single genes. Rather, the problem seems to be driven by contributions from a number of genetic polymorphisms (Allanore et al.; Bogdanos et al.; Brand and Gough; Depaz et al.; Deshmukh et al.; Rainbow et al., 2008). Many genes related to immune function have been identified in the past and in recent genome wide association studies (GWAS) of individuals with autoimmune diseases. Amongst these are PTPN22, CTLA-4, IL-2/IL-21 and, most often, particular MHC alleles, and variants of antigen processing genes (Grumet et al., 1971; McDevitt and Bodmer, 1974; Evnouchidou et al., 2012; Fierabracci et al., 2012; Guerini et al., 2012; Ireland and Unanue, 2012). Why do these variants act together to cause autoimmunity? The consensus is that particular MHC alleles, coupled, in some disease, with variants in the antigen processing machinery, lead to over expression of particular combinations of MHC bound to particular self peptides, which themselves then engage TCRs. Polymorphic variants of other genes then increase the sensitivity of $T$ lymphocytes to engagement of their TCRs and/or reduce the likelihood that aberrant lymphocyte responses will be prevented. Together, these two phenomena contribute to the likelihood of an individual acquiring an autoimmune disease.

With such ideas in mind three hypotheses can be put forward. One suggests that autoimmune disease is most strongly linked to particular $\mathrm{MHC}$ alleles because certain $\mathrm{MHC}$ alleles bind very strongly to certain self peptides (Ada and Rose, 1988). Under these circumstances, the individual contains an overabundance of such $\mathrm{MHC}+$ peptide combinations, thus increasing the likelihood of stimulating a $\mathrm{T}$ cell, even if that cells bears a TCR with relatively low affinity for the $\mathrm{MHC}+$ peptide in question. Thymocytes that can react strongly with $\mathrm{MHC}+$ peptides that are present in the thymus die in that organ, and never appear in the periphery (Kappler et al., 1987; von Boehmer et al., 1989), therefore, in order for this idea to be correct the relevant peptide must be at low concentrations in the thymus but high concentrations elsewhere. This could happen because the concentration is higher in certain tissues of many proteins, for example insulin in the pancreas and myelin basic protein in the nervous system, than in the thymus.

Another hypothesis suggests that particular MHC alleles bind poorly to particular self peptides (Suri et al., 2008). Consequently such $\mathrm{MHC}+$ peptide combinations are present at very low levels in the thymus and cannot effectively cause the death of thymocytes bearing TCRs that react with them. The potentially autoreactive cells mature and appear in the periphery where they may encounter the $\mathrm{MHC}+$ peptide combination at higher concentrations because the protein source of the peptide in question is produced at very high levels in particular tissues. In this situation, the appearance of the autoreactive $T$ cells in the periphery may even be helped by low levels of their stimulating $\mathrm{MHC}+$ peptide ligands in the thymus, since there is evidence that stimulatory $\mathrm{MHC}+$ peptide combinations can, under some circumstances, contribute to positive selection of T cells (Bevan and Hunig, 1981).

A third idea, which could be thought of as a variation of the second hypothesis, suggests that some autoantigenic peptides are not just straightforward breakdown products of their parent protein. Rather, the peptides in question are generated by processes that do not function in the thymus. For example, in some cases tissue specific proteolysis may give rise, in a particular tissue, to a peptide that is not generated in the thymus. If this peptide binds an $\mathrm{MHC}$ allele present in the animal it could drive $\mathrm{T}$ cell responses against the tissue in question. Under other circumstances a particular tissue may produce a modified version of a self peptide which, when bound to MHC, engages some TCRs with high affinity. Alternatively, the modifications could allow the peptides in question to bind to particular MHC alleles more strongly, or in a different register, with the amino acid residues that point out of the MHC groove towards the TCR different from those that were involved in tolerance induction in the thymus. As noted above, the idea that post translationally modified peptides contribute to autoimmunity is particularly likely if the modifications in question are the result of a tissue specific process, a process that occurs in some peripheral tissues but not in the thymus (Marrack and Kappler, 2012; Stadinski et al., $2010 a, 2010 b)$. This idea is also bolstered by the structural finding that many autoimmune TCRs bind to their MHC + self peptide ligands with unusual orientations (Hahn et al., 2005; Li et al., 2005; Sethi et al., 2011; Yin et al., 2011b).

If this last hypothesis about autoimmunity is correct, such diseases are not necessarily failures of any tolerance mechanisms. Rather they are caused by modifications of proteins and/or their peptide products in tissue specific fashions, to give rise to self peptides that are produced only in particular tissues or tissue specific post translational modifications of peptides. In either case the responsible peptides can be viewed as "altered self" or "neoantigens".

Of course any of these hypotheses may apply, under different circumstances. Moreover, regardless of which hypothesis is relevant, a productive $\mathrm{T}$ cell response to the autoantigen will require simultaneous recognition of antigen and delivery of signals 2 and 3 (Fig. 3 ) to the autoreactive T cells

\section{EVIDENCE FOR AUTOIMMUNITY CAUSED BY LOW AFFINITY BINDING OF PEPTIDE TO MHC}

As mentioned in the Introduction, TCRs usually engage MHC + foreign peptide ligands in a diagonal orientation with the CDRs of the TCR placed in fairly reproducible positions on the $\mathrm{MHC}+$ peptide ligand. Over the last 10 years, however, a number of reports have supported the idea that autoimmunity can involve engagement of $\mathrm{MHC}+$ peptide + TCRs in unusual configurations. These unusual configurations could involve unexpected registers for peptide binding to the groove of $\mathrm{MHC}$ and/or, unexpected alignments of autoimmune TCRs on $\mathrm{MHC}+$ peptide combinations. 
As far as unexpected $\mathrm{MHC}+$ peptide registers are concerned, one of the first examples came from work studying the reaction of $\mathrm{T}$ cells with a peptide from the $\mathrm{N}$ terminus of myelin basic protein (MBP) and the mouse MHCII protein, IA $\mathrm{A}^{\mathrm{u}}$, a reaction that drives experimental autoimmune encephalomyelitis (EAE) the experimental model in mice for multiple sclerosis (MS) in humans. The $\mathrm{N}$ terminal amino acid (an alanine) of MBP is a naturally acetylated, a phenomenon which was mimicked in the crystal preparations of the $\mathrm{MHC}+$ peptide + TCR complex by an upstream glycine residue. The crystal structure revealed that the $\mathrm{N}$ terminal alanine is bound to $\mathrm{IA}^{\mathrm{u}}$ at what is usually the $\mathrm{P} 3$ position, the position in the MHC groove that is usually occupied by the third amino acid of the bound peptide (Maynard et al., 2005). The glycine replacing the acetyl group is at P2 and some residues from the construct used to express the MHC + peptide combination lie upstream of P2. Hence, the peptide that contributes to EAE in $I A^{u}$-expressing mice probably begins its engagement with $I A^{u}$ at $\mathrm{P} 2$, via the acetyl group, leaving, presumably, the $\mathrm{P} 1$ position empty, an unusual and perhaps unstable configuration.

Similar conclusions, that recognition of $\mathrm{MHC}+$ peptide combinations that bind weakly to each other can lead to multiple sclerosis in humans, have been reached recently, although in this case the weakly binding peptide appears to occupy the MHC groove entirely, as do most antigenic peptides (Yin et al., 2011b).

Studies on the insulin peptides that contribute to type 1 diabetes in NOD mice lead to related conclusions. Insulin has long been thought to be the source of autoantigenic peptides that are required for induction of type 1 diabetes, in mice at least (Levisetti et al., 2007 Mohan et al., 2007; Nakayama et al., 2007; Jarchum and DiLorenzo, 2009). Although the portion of insulin that contains the culprit peptide has long been known, the precise insulin peptide that drives disease was for many years unknown. It turns out that the crucial product is unexpected, a peptide that binds poorly rather than well to

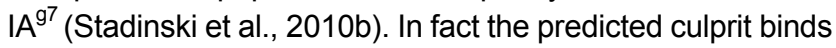
so poorly to $\mid \mathrm{A}^{97}$ that structural studies of its engagement to $\mathrm{MHCll}$ can only be performed with peptide and/or $\mathrm{IA}^{97} \mathrm{mu}-$ tants that have been constructed to improve the reaction between the peptide and $\mathrm{IA}^{\mathrm{g} 7}$. How then, can the peptide bind $\mathrm{MHCll}$ and engage TCRs at significant levels in vivo? Two factors probably contribute. The first is that insulin is present at extremely high levels in the islets of Langerhans, levels that might allow sufficient peptide to be produced to allow detectable levels of the $\mathrm{IA}^{\mathrm{g7}}+$ peptide complex to be present. The second is that islet beta cells might cleave insulin differently than the other cells of the body do, causing removal of amino acid residues of insulin that inhibit binding of the peptide in the diabetogenic register to $\mathrm{IA}^{\mathrm{g} 7}$ and modifying the peptide such that it binds more efficiently to the MHCII protein in question.

The direct consequence of these unstable configurations of peptides binding to $\mathrm{MHC}$ is a destabilization of the whole
TCR-MHC-peptide complex. This may allow autoimmune TCRs that react with this MHC+peptide combination to escape negative selection.

\section{EVIDENCE FOR AUTOIMMUNITY CAUSED BY ENGAGEMENT WITH UNUSUAL TOPOLOGY OF MHC + PEPTIDE BY TCRS}

There are now several examples of autoreactive TCRs that bind to their $\mathrm{MHCll}+$ self peptides ligands at an unusual angle. Amongst these are two human TCRs, Ob.1A12 and $3 A 6$, from the $T$ cells of patients with multiple sclerosis that react with DRB1*1501 bound to a peptide included in MBP 85-101 (Hahn et al., 2005; Li et al., 2005). In both of these cases the TCR engages primarily the $\mathrm{N}$-terminal end of the peptide and that portion of $\mathrm{MHCll}$ which surrounds that part of the peptide. Hence the TCR rotated is heavily tilted towards what is normally illustrated to be the left hand end of the MHC protein (Fig. 2). Recent work on TCRs, Ob.2F3 and Ob.3D1, from one of the same donors indicated that these TCRs also bind the $\mathrm{N}$ terminal end of the peptide (Kato et al., 2010). These TCRs may have low affinity for their self $\mathrm{MHC} /$ self peptide ligands, however, they may also escape tolerance mechanisms in the thymus because their angle of approach to MHC lowers the ability of CD4 to contribute to signaling within the T cell (Adams et al., 2011; Yin et al., 2012a).

Another version of engagement of an autoreactive TCR with MHC + self peptide is illustrated by the HY.1B11 TCR, that binds DQ1+ MBP85-99 (Sethi et al., 2010). In this case the TCR is dramatically tilted on its ligand, such that the germ line encoded Va loops of the TCR do not contact the DQ protein. Whether this unusual orientation of the TCR on MHC contributed to the ability of the T cell bearing this TCR to escape thymic deletion remains to be discovered.

\section{Evidence for autoimmunity caused by $\mathrm{T}$ cell recognition of altered self}

The idea that post translational modifications to proteins and, hence, their peptide products, can lead to autoimmunity. Given the tremendous number of post translational changes to proteins that can occur this is a very attractive idea. For example, a lot of attention has been focused on protein citrullination, a process catalysed by the peptidylarginine deininase enzymes, that converts arginine in proteins to citrulline. The contribution of citrullination to autoimmunity is supported by the fact that antibodies against various citrullinated proteins are found in a number of autoimmune diseases (van Boekel et al., 2002; Rubin and Sonderstrup, 2004; Kuhn et al., 2008). However, $T$ cells specific for these post translationally modified peptides have been difficult to find, partly because the target peptides cannot be screened by conventional genetic means. A recent example comes from studies of type 1 diabetes in non obese diabetic (NOD) mice. The TCR 
BDC2.1 is often used in experiments dealing with the disease. After many years of searching, the protein source of the peptide target of BDC2.1 has been identified. It is chromogranin, a protein that accumulates and is processed in the granules of cells such as the beta cells of the pancreas and in neuroexocrine cells in the brain. A peptide product of the processing of this protein binds to $\mathrm{IA}^{\mathrm{g}^{7}}$ and contributes to type 1 diabetes (Stadinski et al., 2010a). However, the exact nature of the responsible peptide is still unknown. It appears to be a post translationally modified form of a peptide product of the chromagranin protein, a modification that is peculiar to pancreatic beta cells (Haskins and Cooke, 2011).

\section{ALTERED SELF AND ALLERGY}

\section{Metal ions}

At first thought, the idea that allergy involves recognition by $T$ cells of altered self seems unlikely. After all, allergens, such as those provided by ragweed pollen, cat saliva and peanuts are clearly foreign peptides, produced from foreign proteins and recognized, bound to $\mathrm{MHC}$, by host T cells. However, for other allergens the idea of altered self is not so inconceivable. Most straightforwardly, allergies to metal ions, which clearly are not foreign peptides, probably involve $\mathrm{T}$ cell recognition of self MHC bound to a self peptide(s) and simultaneously engaging in an $\mathrm{MHC}$ and peptide specific fashion, the metal ion in question. In such cases the metal ion could be involved in a number of ways. It might bind to the self peptide, to some combination of peptide and $\mathrm{MHC}$ or be engaged in sufficient amounts only when the self peptide, MHC and TCR are present. The metal ion might be involved in some other way, buried beneath the peptide and distorting its upper surface such that the peptide appears "foreign" to the TCR (Fig. 4).

Our recent experiments on $\mathrm{T}$ cell responses to the very common human allergen, $\mathrm{Ni++}$, and the very damaging metal ion, $\mathrm{Be}++$, suggest such reactions. We have previously shown that $\mathrm{Ni++}$ binds strongly to a combination of the human MHCIl protein, DR52c, and some still unknown human peptide. When $\mathrm{Ni++}$ is present, this combination is recognized by a TCR, ANi-2.3, from a human individual who is allergic to $\mathrm{Ni++}$. We have solved the structure of $\mathrm{ANi}-2.3$ bound to DR52c and a peptide that mimics the combination of the unknown human peptide plus $\mathrm{Ni++}$. The structure suggests that the TCR will bind DR52c + self peptide $+\mathrm{Ni}++$ with the conventional orientation. The structure predicts that the $\mathrm{Ni++}$ ion will be bound to a combination of amino acid residues from the $\mathrm{MHC}$ and peptide and thus probably converts the DR52c + self peptide combination from a complex that is not recognized by self $T$ cells to one that represents $a$ form of "altered self" that is recognizable by certain TCRs in $\mathrm{Ni++}$ sensitive individuals (Yin et al., 2012b).

We have come to similar conclusions in collaborative studies with Dr. Andrew Fontenot's laboratory on recognition of $\mathrm{Be}++$ by human $\mathrm{T}$ cells. Immunity to $\mathrm{Be}++$ occurs in individuals who are involved in machining beryllium and requires expression in the patient of DP2 or some related DP protein. Berylliosis is a serious and potentially lethal lung disease. We have shown that $\mathrm{Be}++$ binds very strongly to DP2 and our preliminary Xray crystallographically solved structures of DP2 + a mimitope peptide plus $\mathrm{Be}++$ with a TCR from a beryllium-sensitive patient indicate, again, that the metal ion converts a combination that is not seen by $\mathrm{T}$ cells to a form of "altered self" that is immunogenic. As in the case of $\mathrm{Ni++}$, the beryllium ion is predicted to be bound to a combination of amino acids from both DP2 and the self peptide lying in the groove. In this state it then participates in engagement of a $\mathrm{DP} 2+\mathrm{Be}++$ specific TCR (Clayton et al., in preparation).

\section{Drugs}

A clear example of altered self generated by a drug came from the recent studies of Illing et al. (2012). The scientists examined reactivity to the drug Abacavir, a small molecule used to treat HIV infections. Individuals who express HLA-B*57:01 can become sensitive to the drug and develop Abacavir hypersensitivity syndrome (AHS). Illing et al. showed that Abacavir binds to the bottom of the HLA-B*57:01 groove, changing the spectrum of peptides that can bind the groove. They obtained similar results with carbamazepine, an anti-epileptic drug that causes hypersensitivity in HLA-B*15:02 expressing individuals. Thus in both cases the severe hypersensitivity reactions are probably due to massive activation of CD8 T cells to self MHC bound to a collection of self peptides to which the $T$ cells were not tolerized in the thymus. How frequently these findings will extend to other drug allergens, such as aspirin, remains to be seen. Nevertheless the current findings describe dramatic examples of the consequences of recognition of altered self by $T$ cells. They perhaps support the findings, years ago, by Bevan and Hunig

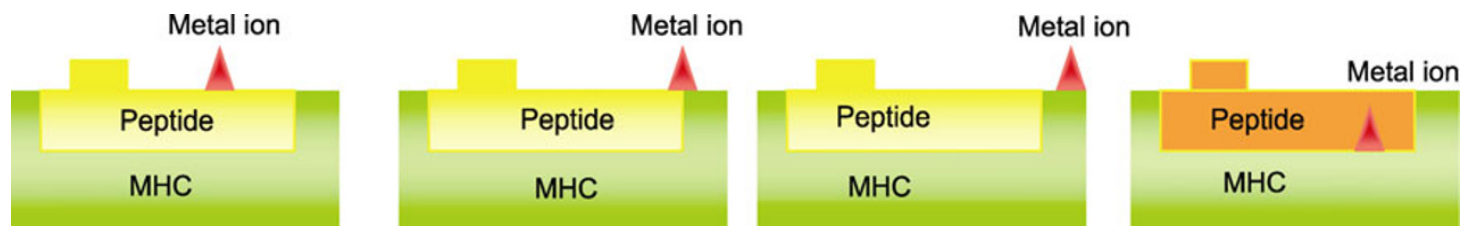

Figure 4. Small molecules such as metal ions may change the structure of self MHC + self peptide complexes in various ways. Metal ions or drugs may be able to bind to and change the aspect of self $\mathrm{MHC}+$ self peptides by binding to the upper surface of the peptide, by binding to a combination of peptide $+\mathrm{MHC}$, by binding just to the $\mathrm{MHC}$, or by engaging the groove of the MHC protein, thus changing the spectrum of self peptides bound to the MHC, rendering the MHC + peptide combination now "foreign". 
that $T$ cells react more powerfully to self $\mathrm{MHC}$ bound to altered peptides than to foreign MHC (Bevan and Hunig, 1981).

\section{CONCLUSIONS}

A great number of post translation modifications of proteins that are possible, phosphorylation, glycoslyation, conversion of amino acids such as asparagines to aspartic acid, acetylation, lipidation, sulfation, methylation, the list of possibilities is tremendously long. Given this, it is perhaps surprising that autoimmunity caused by recognition of post translationally modified peptides is not more common that it is. Perhaps the fact that such diseases are rare is a tribute to the efficiency of thymic tolerance, perhaps all these modifications occur in the thymus and can thus usually participate in deletion of potentially autoreactive thymocytes. Alternatively, $T$ cells that can react with all these post translationally modified peptides may be held down by the processes of peripheral tolerance, such as regulatory $T$ cells or anergy induction. Whatever the processes are that usually prevent $T$ cell reaction with "altered self", they usually operate very effectively.

The parallels between autoreactivity caused by recognition of "altered self" peptides and allergy caused by modifications of self $\mathrm{MHC}+$ self peptides by small molecule allergens are interesting. Both can involve recognition by $T$ cells of self $\mathrm{MHC}+$ a self peptide. For autoreactivity, the self peptide may be modified by post translational process, for small molecule driven allergy, the self peptide bound to $\mathrm{MHC}$ may be affected by the small molecule itself. Some years ago, experiments suggested that the mature $T$ cells in an individual are more likely to react strongly with MHC proteins that are closely related to the MHC expressed in the individual. That is, some element of relationship between MHCs affects the likelihood that $T$ cells will cross react with the unfamiliar target. Perhaps this argument applies also to autoreactivity and small molecule allergy. That is, although most potentially autoreactive $T$ cells are deleted in the thymus, those that survive might be more likely to react with self $\mathrm{MHC}+$ a peptide related to self (an altered self peptide) in the periphery. The same argument might apply to allergic reactions in which the small allergen, a metal ion or drug, slightly alters the aspect of self MHC + self peptide. Only further experiments will test these ideas.

\section{ACKNOWLEDGEMENTS}

This work was supported by USPHS grants Al-18785 and 22295 . The authors have no conflict of interest to report with regard to this paper.

\section{REFERENCES}

Ada, G.L., and Rose, N.R. (1988). The initiation and early development of autoimmune diseases. Clin Immunol Immunopathol 47, 3-9.

Adams, J.J., Narayanan, S., Liu, B., Birnbaum, M.E., Kruse, A.C.,
Bowerman, N.A., Chen, W., Levin, A.M., Connolly, J.M., Zhu, C., et al. (2011). T cell receptor signaling is limited by docking geometry to peptide-major histocompatibility complex. Immunity 35, 681-693.

Alarcon, B., Mestre, D., and Martinez-Martin, N. (2011). The immunological synapse: a cause or consequence of T-cell receptor triggering? Immunology 133, 420-425.

Allanore, Y., Saad, M., Dieude, P., Avouac, J., Distler, J.H., Amouyel, P., Matucci-Cerinic, M., Riemekasten, G., Airo, P., Melchers, I., et al. (2011). Genome-wide scan identifies TNIP1, PSORS1C1, and RHOB as novel risk loci for systemic sclerosis. PLoS Genet 7 , e1002091.

Anderson, M.S., Venanzi, E.S., Klein, L., Chen, Z., Berzins, S.P., Turley, S.J., von Boehmer, H., Bronson, R., Dierich, A., Benoist, C., et al. (2002). Projection of an immunological self shadow within the thymus by the aire protein. Science 298, 1395-1401.

Banchereau, J., and Steinman, R.M. (1998). Dendritic cells and the control of immunity. Nature 392, 245-252.

Bevan, M.J., and Hunig, T. (1981). T cells respond preferentially to antigens that are similar to self $\mathrm{H}-2$. Proc Natl Acad Sci U S A 78, 1843-1847.

Bluestone, J.A. (1995). New perspectives of CD28-B7-mediated T cell costimulation. Immunity 2, 555-559.

Bluthmann, H., Kisielow, P., Uematsu, Y., Malissen, M., Krimpenfort, P., Berns, A., von Boehmer, H., and Steinmetz, M. (1988). T-cell-specific deletion of T-cell receptor transgenes allows functional rearrangement of endogenous alpha- and beta-genes. Nature 334, 156-159.

Bogdanos, D.P., Smyk, D.S., Rigopoulou, E.I., Mytilinaiou, M.G., Heneghan, M.A., Selmi, C., and Gershwin, M.E. (2011). Twin studies in autoimmune disease: genetics, gender and environment. J Autoimmun 38, J156-169.

Brand, O.J., and Gough, S.C. (2012). Immunogenetic mechanisms leading to thyroid autoimmunity: recent advances in identifying susceptibility genes and regions. Curr Genomics 12, 526-541.

Browne, S.K., and Holland, S.M. (2010). Immunodeficiency secondary to anticytokine autoantibodies. Curr Opin Allergy Clin Immunol 10, 534-541.

Burrows, S.R., Chen, Z., Archbold, J.K., Tynan, F.E., Beddoe, T., Kjer-Nielsen, L., Miles, J.J., Khanna, R., Moss, D.J., Liu, Y.C., et al. (2010). Hard wiring of $T$ cell receptor specificity for the major histocompatibility complex is underpinned by TCR adaptability. Proc Natl Acad Sci U S A 107, 10608-10613.

Callahan, M.K., Wolchok, J.D., and Allison, J.P. (2010). Anti-CTLA-4 antibody therapy: immune monitoring during clinical development of a novel immunotherapy. Semin Oncol 37, 473-484.

Colf, L.A., Bankovich, A.J., Hanick, N.A., Bowerman, N.A., Jones, L.L., Kranz, D.M., and Garcia, K.C. (2007). How a single T cell receptor recognizes both self and foreign MHC. Cell 129, 135-146.

Croft, M. (2009). The role of TNF superfamily members in T-cell function and diseases. Nat Rev Immunol 9, 271-285.

Dai, S., Huseby, E.S., Rubtsova, K., Scott-Browne, J., Crawford, F., Macdonald, W.A., Marrack, P., and Kappler, J.W. (2008). Crossreactive $T$ Cells spotlight the germline rules for alphabeta $T$ cell-receptor interactions with MHC molecules. Immunity 28, 324-334. 
Day, E.B., Guillonneau, C., Gras, S., La Gruta, N.L., Vignali, D.A., Doherty, P.C., Purcell, A.W., Rossjohn, J., and Turner, S.J. (2011). Structural basis for enabling T-cell receptor diversity within biased virus-specific CD8+ T-cell responses. Proc Natl Acad Sci U S A 108, 9536-9541.

Depaz, R., Granger, B., Cournu-Rebeix, I., Bouafia, A., and Fontaine, B. (2011). Genetics for understanding and predicting clinical progression in multiple sclerosis. Rev Neurol (Paris) 167, 791-801.

Deshmukh, H.A., Maiti, A.K., Kim-Howard, X.R., Rojas-Villarraga, A., Guthridge, J.M., Anaya, J.M., and Nath, S.K. (2011). Evaluation of 19 autoimmune disease-associated loci with rheumatoid arthritis in a Colombian population: evidence for replication and gene-gene interaction. J Rheumatol 38, 1866-1870.

Dhein, J., Walczak, H., Baumler, C., Debatin, K.M., and Krammer, P.H. (1995). Autocrine T-cell suicide mediated by APO-1/(Fas/CD95). Nature 373, 438-441.

Dinarello, C.A. (2002). The IL-1 family and inflammatory diseases. Clin Exp Rheumatol 20, S1-13.

Dolfi, D.V., and Katsikis, P.D. (2007). CD28 and CD27 costimulation of CD8+ T cells: a story of survival. Adv Exp Med Biol 590, 149-170.

Evnouchidou, I., Birtley, J., Seregin, S., Papakyriakou, A., Zervoudi, E., Samiotaki, M., Panayotou, G., Giastas, P., Petrakis, O., Georgiadis, D., et al. (2012). A common single nucleotide polymorphism in endoplasmic reticulum aminopeptidase 2 induces a specificity switch that leads to altered antigen processing. J Immunol 189, 2383-2392

Feng, D., Bond, C.J., Ely, L.K., Maynard, J., and Garcia, K.C. (2007). Structural evidence for a germline-encoded T cell receptor-major histocompatibility complex interaction 'codon'. Nat Immunol 8, 975-983.

Fierabracci, A., Milillo, A., Locatelli, F., and Fruci, D. (2012). The putative role of endoplasmic reticulum aminopeptidases in autoimmunity: Insights from genomic-wide association studies. Autoimmun Rev. (In Press).

Gambineri, E., Torgerson, T.R., and Ochs, H.D. (2003). Immune dysregulation, polyendocrinopathy, enteropathy, and X-linked inheritance (IPEX), a syndrome of systemic autoimmunity caused by mutations of FOXP3, a critical regulator of T-cell homeostasis. Curr Opin Rheumatol 15, 430-435.

Garcia, K.C., Adams, J.J., Feng, D., and Ely, L.K. (2009). The molecular basis of TCR germline bias for MHC is surprisingly simple. Nat Immunol 10, 143-147.

Garcia, K.C., Degano, M., Pease, L.R., Huang, M., Peterson, P.A., Teyton, L., and Wilson, I.A. (1998). Structural basis of plasticity in $\mathrm{T}$ cell receptor recognition of a self peptide-MHC antigen. Science 279, 1166-1172.

Garcia, K.C., Degano, M., Stanfield, R.L., Brunmark, A., Jackson, M.R., Peterson, P.A., Teyton, L., and Wilson, I.A. (1996). An alphabeta $\mathrm{T}$ cell receptor structure at $2.5 \mathrm{~A}$ and its orientation in the TCR-MHC complex. Science 274, 209-219.

Garcia, K.C., Teyton, L., and Wilson, I.A. (1999). Structural basis of T cell recognition. Annu Rev Immunol 17, 369-397.

Grumet, F.C., Coukell, A., Bodmer, J.G., Bodmer, W.F., and McDevitt, H.O. (1971). Histocompatibility (HL-A) antigens associated with systemic lupus erythematosus. A possible genetic predisposition to disease. N Engl J Med 285, 193-196.
Guerini, F.R., Cagliani, R., Forni, D., Agliardi, C., Caputo, D., Cassinotti, A., Galimberti, D., Fenoglio, C., Biasin, M., Asselta, R., et al. (2012). A functional variant in ERAP1 predisposes to multiple sclerosis. PLoS One 7, e29931.

Hahn, M., Nicholson, M.J., Pyrdol, J., and Wucherpfennig, K.W. (2005). Unconventional topology of self peptide-major histocompatibility complex binding by a human autoimmune $\mathrm{T}$ cell receptor. Nat Immunol 6, 490-496.

Haskins, K., and Cooke, A. (2011). CD4 T cells and their antigens in the pathogenesis of autoimmune diabetes. Curr Opin Immunol 23, 739-745.

Heino, M., Peterson, P., Kudoh, J., Shimizu, N., Antonarakis, S.E., Scott, H.S., and Krohn, K. (2001). APECED mutations in the autoimmune regulator (AIRE) gene. Hum Mutat 18, 205-211.

Hintzen, R.Q., de Jong, R., Lens, S.M., and van Lier, R.A. (1994). CD27: marker and mediator of T-cell activation? Immunol Today 15, 307-311.

Illing, P.T., Vivian, J.P., Dudek, N.L., Kostenko, L., Chen, Z., Bharadwaj, M., Miles, J.J., Kjer-Nielsen, L., Gras, S., Williamson, N.A., et al. (2012). Immune self-reactivity triggered by drug-modified HLA-peptide repertoire. Nature 486, 554-558.

Inaba, K., Metlay, J.P., Crowley, M.T., Witmer-Pack, M., and Steinman, R.M. (1990). Dendritic cells as antigen presenting cells in vivo. Int Rev Immunol 6, 197-206.

Ireland, J.M., and Unanue, E.R. (2012). Processing of proteins in autophagy vesicles of antigen-presenting cells generates citrullinated peptides recognized by the immune system. Autophagy 8, 429-430..

Jarchum, I., and DiLorenzo, T.P. (2009). Ins2 deficiency augments spontaneous HLA-A*0201-restricted T cell responses to insulin. J Immunol 184, 658-665.

Jenkins, M.K., and Schwartz, R.H. (1987). Antigen presentation by chemically modified splenocytes induces antigen-specific $T$ cell unresponsiveness in vitro and in vivo. J Exp Med 165, 302-319.

Kappler, J.W., Roehm, N., and Marrack, P. (1987). T cell tolerance by clonal elimination in the thymus. Cell 49, 273-280.

Kato, Z., Stern, J.N., Nakamura, H.K., Miyashita, N., Kuwata, K., Kondo, N., and Strominger, J.L. (2010). The autoimmune TCR-Ob.2F3 can bind to MBP85-99/HLA-DR2 having an unconventional mode as in TCR-Ob.1A12. Mol Immunol 48, 314-320.

Kuhn, K.A., Cozine, C.L., Tomooka, B., Robinson, W.H., and Holers, V.M. (2008). Complement receptor CR2/CR1 deficiency protects mice from collagen-induced arthritis and associates with reduced autoantibodies to type II collagen and citrullinated antigens. Mol Immunol 45, 2808-2819.

Lafferty, K.J., and Cunningham, A.J. (1975). A new analysis of allogeneic interactions. Aust J Exp Biol Med Sci 53, 27-42.

Levisetti, M.G., Suri, A., Petzold, S.J., and Unanue, E.R. (2007). The insulin-specific $T$ cells of nonobese diabetic mice recognize a weak MHC-binding segment in more than one form. J Immunol 178, 6051-6057.

Li, Y., Huang, Y., Lue, J., Quandt, J.A., Martin, R., and Mariuzza, R.A. (2005). Structure of a human autoimmune TCR bound to a myelin basic protein self-peptide and a multiple sclerosis-associated MHC class II molecule. EMBO J 24, 2968-2979.

Marrack, P., and Kappler, J.W. (2012). Do MHCII-presented neoantigens drive type 1 diabetes and other autoimmune 
diseases? Cold Spring Harb Perspect Med 2, a007765.

Marrack, P., Scott-Browne, J.P., Dai, S., Gapin, L., and Kappler, J.W. (2008). Evolutionarily conserved amino acids that control TCR-MHC interaction. Annu Rev Immunol 26, 171-203.

Maynard, J., Petersson, K., Wilson, D.H., Adams, E.J., Blondelle, S.E., Boulanger, M.J., Wilson, D.B., and Garcia, K.C. (2005). Structure of an autoimmune $\mathrm{T}$ cell receptor complexed with class II peptide-MHC: insights into MHC bias and antigen specificity. Immunity 22, 81-92.

McDevitt, H.O., and Bodmer, W.F. (1974). HL-A, immune-response genes, and disease. Lancet 1, 1269-1275.

Mohan, J.F., Levisetti, M.G., Calderon, B., Herzog, J.W., Petzold, S.J., and Unanue, E.R. (2010). Unique autoreactive T cells recognize insulin peptides generated within the islets of Langerhans in autoimmune diabetes. Nat Immunol 11, 350-354.

Nakayama, M., Beilke, J.N., Jasinski, J.M., Kobayashi, M., Miao, D., Li, M., Coulombe, M.G., Liu, E., Elliott, J.F., Gill, R.G., et al. (2007). Priming and effector dependence on insulin B:9-23 peptide in NOD islet autoimmunity. J Clin Invest 117, 1835-1843.

Pardoll, D.M. (2012). The blockade of immune checkpoints in cancer immunotherapy. Nat Rev Cancer 12, 252-264.

Rainbow, D.B., Esposito, L., Howlett, S.K., Hunter, K.M., Todd, J.A., Peterson, L.B., and Wicker, L.S. (2008). Commonality in the genetic control of Type 1 diabetes in humans and NOD mice: variants of genes in the IL-2 pathway are associated with autoimmune diabetes in both species. Biochem Soc Trans 36, 312-315.

Ramsdell, F. (2003). Foxp3 and natural regulatory T cells: key to a cell lineage? Immunity 19, 165-168.

Ramsey, C., Winqvist, O., Puhakka, L., Halonen, M., Moro, A., Kampe, O., Eskelin, P., Pelto-Huikko, M., and Peltonen, L. (2002). Aire deficient mice develop multiple features of APECED phenotype and show altered immune response. Hum Mol Genet 11, 397-409.

Reiser, J.B., Darnault, C., Gregoire, C., Mosser, T., Mazza, G., Kearney, A., van der Merwe, P.A., Fontecilla-Camps, J.C., Housset, D., and Malissen, B. (2003). CDR3 loop flexibility contributes to the degeneracy of TCR recognition. Nat Immunol 4, 241-247.

Rubin, B., and Sonderstrup, G. (2004). Citrullination of self-proteins and autoimmunity. Scand J Immunol 60, 112-120.

Sethi, D.K., Schubert, D.A., Anders, A.K., Heroux, A., Bonsor, D.A., Thomas, C.P., Sundberg, E.J., Pyrdol, J., and Wucherpfennig, K.W. (2011). A highly tilted binding mode by a self-reactive T cell receptor results in altered engagement of peptide and MHC. J Exp Med 208, 91-102.

Sharpe, A.H. (2009). Mechanisms of costimulation. Immunol Rev 229, 5-11.

Sloan-Lancaster, J., and Allen, P.M. (1995). Signalling events in the anergy induction of T helper 1 cells. Ciba Found Symp 195, 189-196; discussion 196-202.

Sneller, M.C., Wang, J., Dale, J.K., Strober, W., Middelton, L.A., Choi, Y., Fleisher, T.A., Lim, M.S., Jaffe, E.S., Puck, J.M., et al. (1997). Clincal, immunologic, and genetic features of an autoimmune lymphoproliferative syndrome associated with abnormal lymphocyte apoptosis. Blood 89, 1341-1348.

Stadinski, B.D., Delong, T., Reisdorph, N., Reisdorph, R., Powell,
R.L., Armstrong, M., Piganelli, J.D., Barbour, G., Bradley, B., Crawford, F., et al. (2010a). Chromogranin A is an autoantigen in type 1 diabetes. Nat Immunol 11, 225-231.

Stadinski, B.D., Zhang, L., Crawford, F., Marrack, P., Eisenbarth, G.S., and Kappler, J.W. (2010b). Diabetogenic T cells recognize insulin bound to IAg7 in an unexpected, weakly binding register. Proc Natl Acad Sci U S A 107, 10978-10983.

Steinman, R.M., and Inaba, K. (1985). Stimulation of the primary mixed leukocyte reaction. Crit Rev Immunol 5, 331-348.

Steinman, R.M., Koide, S., Witmer, M., Crowley, M., Bhardwaj, N., Freudenthal, P., Young, J., and Inaba, K. (1988). The sensitization phase of T-cell-mediated immunity. Ann N Y Acad Sci 546, 80-90.

Suri, A., Levisetti, M.G., and Unanue, E.R. (2008). Do the peptide-binding properties of diabetogenic class II molecules explain autoreactivity? Curr Opin Immunol 20, 105-110.

Tynan, F.E., Burrows, S.R., Buckle, A.M., Clements, C.S., Borg, N.A., Miles, J.J., Beddoe, T., Whisstock, J.C., Wilce, M.C., Silins, S.L., et al. (2005). T cell receptor recognition of a 'super-bulged' major histocompatibility complex class I-bound peptide. Nat Immunol 6, 1114-1122.

Tynan, F.E., Reid, H.H., Kjer-Nielsen, L., Miles, J.J., Wilce, M.C., Kostenko, L., Borg, N.A., Williamson, N.A., Beddoe, T., Purcell, A.W., et al. (2007). A T cell receptor flattens a bulged antigenic peptide presented by a major histocompatibility complex class I molecule. Nat Immunol 8, 268-276.

van Boekel, M.A., Vossenaar, E.R., van den Hoogen, F.H., and van Venrooij, W.J. (2002). Autoantibody systems in rheumatoid arthritis: specificity, sensitivity and diagnostic value. Arthritis Res 4 , 87-93.

von Boehmer, H., Teh, H.S., and Kisielow, P. (1989). The thymus selects the useful, neglects the useless and destroys the harmful. Immunol Today 10, 57-61.

Watts, T.H. (2010). Staying alive: T cell costimulation, CD28, and Bcl-xL. J Immunol 185, 3785-3787.

Wherry, E.J., Ha, S.J., Kaech, S.M., Haining, W.N., Sarkar, S., Kalia, V., Subramaniam, S., Blattman, J.N., Barber, D.L., and Ahmed, R. (2007). Molecular signature of CD8+ T cell exhaustion during chronic viral infection. Immunity 27, 670-684.

Wildin, R.S., Smyk-Pearson, S., and Filipovich, A.H. (2002). Clinical and molecular features of the immunodysregulation, polyendocrinopathy, enteropathy, $X$ linked (IPEX) syndrome. J Med Genet 39, 537-545.

Yin, L., Crawford, F, Marrack, P., Kappler, J.W. and Dai, S. (2012b) T-cell receptor (TCR) interaction with peptides that mimic nickel offers insight into nickel contact allergy. Proc Natl Acad Sci U S A 109, 18517-18522.

Yin, L., Huseby, E., Scott-Browne, J., Rubtsova, K., Pinilla, C., Crawford, F., Marrack, P., Dai, S., and Kappler, J.W. (2011a). A single $T$ cell receptor bound to major histocompatibility complex class I and class II glycoproteins reveals switchable TCR conformers. Immunity 35, 23-33.

Yin, Y., Li, Y., Kerzic, M.C., Martin, R., and Mariuzza, R.A. (2011b). Structure of a TCR with high affinity for self-antigen reveals basis for escape from negative selection. EMBO J 30, 1137-1148.

Yin, Y., Wang, X.X., and Mariuzza, R.A. (2012a). Crystal structure of a complete ternary complex of T-cell receptor, peptide-MHC, and CD4. Proc Natl Acad Sci U S A 109, 5405-5410. 